\title{
EDITORIAL
}

\section{CRISE DO PROJETO DEMOCRÁTICO DE EDUCAÇÃO}

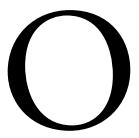

momento político, econômico e cultural experimentado pela sociedade brasileira é, sob todos os pontos de vista, preocupante. A educação, em todos os níveis, integra esse cenário de preocupaçóes e incertezas. A superaçáo da ditadura na década de 1980 e as conquistas que se seguiram haviam gerado muitas expectativas e esperanças que se traduziram na Constituição Federal de 1988 e, ainda que parcialmente, também na Lei de Diretrizes e Bases (LDB) de 1996. Seguiram-se quase duas décadas de esforços e lutas buscando, de um lado, realizar os direitos estabelecidos na Constituição e, de outro lado, enfrentar orientaçóes ancoradas na nova gestão pública, as quais, desde os anos 1990, balizam políticas e hoje consubstanciam as reformas educacionais.

Efetivamente, se muito foi alcançado, com o passar do tempo e da sucessão dos governos, esperanças de mudanças mais profundas e duradouras foram frustradas pela resistência e pela defesa dos privilégios por parte das elites, avessas à ideia de uma sociedade mais digna, igual e humana. Nesse período de retrocessos, privilégios preservados foram, em muitos casos, ampliados.

A história mais recente da educação em nosso país é paradigmática desse cenário. As conquistas alcançadas, apresentadas na melhora geral dos indicadores educacionais, e almejadas, conforme expresso nos processos e documentos das Conferências Nacionais de Educação (CONAES), bem como na elaboração do Plano Nacional de Educação (PNE), foram, aos poucos, ora de forma velada, ora de maneira ostensiva, sendo subvertidas e esvaziadas pelas estratégias das elites políticas e econômicas conservadoras. Hoje nos encontramos em meio a um momento de inoperante caos e frustração ao qual nem os mais pessimistas imaginavam que pudéssemos chegar. Não se trata apenas de lentidão ou estagnação, mas de verdadeiro retrocesso em termos de política educacional. Exemplos notórios são as reformas e propostas de mudança legislativa ora em curso, entre as quais merece destaque a Escola sem Partido. Não se trata de retrocessos apenas porque as elites, em meados da última década do século passado e início dos anos do novo século (2000), se reestruturam, mas também porque os setores progressistas não resistiram às imposiçôes do pragmatismo político e econômico.

Como é comum entre nós, cedemos à tentação de culpar setores sociais, agremiaçóes políticas ou mesmo figuras públicas individuais quando se trata de

DOI: 10.1590/ES0101-73302017v38n140ED 
problemas conjunturais e culturais mais amplos e profundos. Ainda nos encontramos em meio às turbulências e aos torvelinhos dessas águas turvas sem saber como náo afogar. Procuramos nos agarrar aqui e acolá e perdemos de vista o fluxo do grande rio que não cessa de nos levar. Essa visão mais ampliada dos grandes movimentos globais talvez nos ajude a entender melhor o curso, as interconexóes, as determinaçôes, bem como as dificuldades, que enfrentamos. O grande cenário político, econômico, tecnológico é o neoliberalismo ou pós-neoliberalismo, como preferem dizer Dardot e Laval (1916), para quem o capitalismo pauta toda a orientação de educação nos moldes da formação de capital humano a serviço do sistema econômico.

O modelo centralizador, gerencial e monetarista como são tratadas as questôes da educação insiste numa plataforma pedagógica há tempo objeto de severas críticas por parte dos setores mais conscientes e críticos que reconhecem os limites de uma agenda de desenvolvimento político, tecnológico e humano pautada nos moldes de uma estrita e estreita formação de capital humano a serviço do modelo econômico (pós-)neoliberal, o qual, ademais, vem dando evidentes sinais de falência e no qual, sabidamente, não há postos de trabalho qualificados para todos, como sugerem programas educativos alinhados com a teoria do capital humano. A desconsideraçẫo das especificidades culturais e socioeconômicas por parte de funcionários sistêmicos revela forte tendência de subserviência e notória vontade de adaptação ao neoliberalismo. O simples fato de se considerar a possibilidade de congelamento, por 20 anos, dos investimentos em políticas públicas (Emenda Constitucional no 95, de 2016) inviabiliza por completo as metas do PNE, que prevê ou, talvez se deva dizer, previa a destinação de $10 \%$ do produto interno bruto (PIB) para a educação pública.

Com a redução das orientações pedagógicas aos interesses de grandes corporaçóes e de suas representações, projetos pedagógicos são postos a serviço do todo funcional sistêmico que nega o humano e suas múltiplas dimensóes. Para tais orientaçôes, a pessoa é enquadrada em padróes prefixados e desconectados do que representa ser essencial ao humano, que são a liberdade e a autodeterminaçáa. Não por acaso, a educação básica pública vê-se condicionada a aderir às reformas da educação do atual governo desviando-se da luta pela formação do ser humano enquanto sujeito livre e autônomo, alinhando-se a um modelo de educação reduzido à aprendizagem de alguns campos do conhecimento disciplinarmente organizados.

No Brasil, em meio ao cenário de contrarreformas e retaliações institucionais emudecem as esperanças e se desfigura o projeto de uma sociedade mais digna e justa respaldado pela Constituição Federal de 1988. A imposição arbitrária de reformas por parte dos governos, sem a devida participação dos setores representativos da população mediante instâncias participativas, como ocorreu na destituição unilateral do Fórum Nacional de Educação (FNE), é sinal evidente de autoritarismo voltado ao desmanche e à privatização da educação pública brasileira, inaugurando entre nós a onda neoconservadora verificada em âmbito global. 
Expressão desse neoconservadorismo encontra-se, também, no chamado movimento Escola sem Partido, verdadeira imposiçâo da lei da mordaça no país, em franca oposição aos objetivos públicos da educação e aos princípios da liberdade de ensinar, aprender e estudar, bem como à gestâo democrática e ao pluralismo de concepçôes pedagógicas asseguradas pela Constituição Federal de 1988, nos artigos 205 e 206, e reafirmados na LDB de 1996. Segundo princípios constitucionais, o processo de elaboração de políticas públicas deve ser conduzido com autoridade e sem autoritarismo, ou seja, por meio do debate público, livre, plural e democrático, procedimentos indissociáveis da formulação de políticas públicas, normas e leis, de propostas e de práticas curriculares que, no campo educacional, representam elementos constituintes da formação do sujeito humano.

Nesse sentido, se a Escola sem Partido limita a atuação do professor à transmissão de conteúdos supostamente neutros e objetivos, onde fica a formação do sujeito? Como se formam as bases de sua autonomia e dignidade, senão por meio do livre debate de ideias e pelas relações respeitosamente dialógicas que sấo estabelecidas entre os agentes educacionais? Sem o debate livre de ideias, não pode haver formação humanista, condição para a formação de indivíduos autônomos e eticamente responsáveis. Sendo a ordem concorrencial e competitiva o fio condutor da lógica educativa, o princípio da individualização (HONNETH, 2002) também será o paradoxal princípio estruturante do tecido social, sem vida comum, sem reconhecimento mútuo, com os mesmos excluídos de sempre.

Nosso desafio é, mais uma vez, encontrar formas e estruturas teórico-práticas que sustentem um projeto educacional participativo/democrático favorável tanto ao desenvolvimento subjetivo quanto ao sucesso econômico. A educação não pode ser posta a serviço desse modelo, ou seja, formar para a subserviência a um sistema econômico pelo medo de se tornar supérfluo e ser excluído (SENNET, 2015). À medida que a ditadura da economia neoliberal se torna um fato, a revolução contra esse sistema se transforma em um dever que cabe também à educação cumprir. Vale lembrar aqui a imagem dos "intelectuais de duas categorias", usada por Chomsky (1917). De um lado, estão os que se preocupam com as causas da liberdade, da justiça, da democracia e da integração social e, de outro, os tecnocratas orientados para a defesa, a preservaçáo e o desenvolvimento do sistema político/econômico vigente. A instrumentalização da formação subjetiva e ética das crianças e dos jovens a favor dos interesses mercantis representa a submissão do homem ao sistema, isto é, a redução dos interesses humanos aos interesses do sistema econômico. Como consequência, a educação do ser humano reduz-se, crescentemente, ao desenvolvimento racional do domínio de conhecimentos e técnicas necessárias ao sucesso profissional no contexto do sistema econômico dominante.

O preço dessa coincidência é a anulação do sujeito que se reduz à sua competência produtiva, segundo um portfólio de capacidades que interessam ao capital. Essa geminação entre as aspiraçóes do indivíduo e da empresa representa hoje um dos temas centrais do debate da ética e da formação do ser humano. 
Náo mais importa o que é ou deva ser o sujeito humano enquanto tal, mas o que e o quanto ele pode, por suas próprias competências, aportar ao desenvolvimento do sistema. Segundo essa compreensáo sistêmica, a escola é um mecanismo que pode (e deve) ser usado para internalizar, ou seja, transferir aos indivíduos a mesma lógica competitiva regida pelos interesses financeiros e mercantis. $\mathrm{O}$ sentido humano e as relações econômicas confundem-se, justificando, assim, pela inarredável lógica mercantil, a injustiça e a exclusão social como inerentes à própria condição humana da desigualdade social. Trata-se de uma conversão do olhar sobre si mesmo como ato social, político e ético por excelência, para o olhar externo, que instrumentaliza e insere o indivíduo na mecânica do sistema e lhe impóe as coordenadas de vida boa e sucesso individual.

Dessa maneira, imbricam-se sentido humano e sucesso sistêmico anulando a dimensão política, social, ética e subjetiva do humano. Não importa perguntar se os procedimentos pedagógicos e seus resultados são bons ou maus, verdadeiros ou falsos do ponto de vista subjetivo e social, mas se são estratégicos para o funcionamento do sistema econômico. Impóe-se a ascese do desempenho, da competência e da competitividade que não tem o sujeito, mas o sistema econômico como objetivo. Com isso, ocorre uma inversão profunda e radical entre a autonomia do humano e a autonomia do sistema; não é mais o sujeito de direito que cabe à educaçáo formar, mas um indivíduo alienado de si e posto a serviço dos objetivos e interesses do sistema.

Nos termos das políticas educacionais atualmente em curso, o que mais importa é a tarefa de despolitizar e ajustar sistemicamente as pessoas segundo as supostamente incontornáveis exigências da globalização, em flagrante desrespeito ao inequívoco dispositivo constitucional, segundo o qual cabe à educaçáo promover o pleno desenvolvimento da pessoa, seu preparo para o exercício da cidadania e sua qualificaçâo para o trabalho. Em sentido oposto, o interesse do sistema consiste na autotransformação do sujeito em agente produtivo cujas ambições de autoestima não ultrapassam os limites da mais estrita subserviência aos interesses do capital. Nos termos das políticas públicas gerenciais atualmente em curso, setores referentes aos direitos subjetivos como educação, saúde e segurança deixam de ser objeto de leis positivas para serem expostos à precarização da responsabilidade individual. Com isso, os setores sociais destituídos de recursos são condenados ao seu próprio destino e responsabilizados por seu fracasso. A educação pública, direito de todos $e$ dever do Estado, é abandonada e, o quanto possível, privatizada em nome da falta de recursos que, no mais, não faltam a outros setores de maior interesse econômico.

A ética individualista, hoje largamente difundida, que transforma o sujeito autônomo em sujeito autômato guiado pelo "grande outro" (ZIZEK, 2016), o mercado, é usada como amparo ontológico para justificar e atribuir ao indivíduo, ou seja, para personalizar a responsabilidade e os custos pelos desequilíbrios e injustiças sociais entre ricos e pobres, incluídos e excluídos, cultos e ignorantes, saudáveis e doentes, empregados e desempregados. Essa orientação personalista 
neoliberal, hoje determinante dos rumos da sociedade, interfere profundamente no direito das pessoas à integraçáo sociocultural e material, reservado apenas aos que oferecem o desempenho técnico-profissional esperado.

Conceitos como "reificação" e "instrumentalização" do sujeito, mencionados por Adorno e Horkheimer (1985), perdem sua natureza passiva à medida que o próprio sujeito passa a buscar ativamente, pela educação, sua transformação em capital humano adequado às expectativas do sistema econômico. Os procedimentos e exigências técnicos, impostos pelo sistema em nome da eficiência e do desenvolvimento econômico, ultrapassam o limiar de qualquer visão política, social e ética do sujeito. Perde-se a noção do bem público acessível a todos por direito; dissolve-se o conceito de cidadania; transforma-se a educação/formaçáo em aprendizagem e treinamento. Essa submissão quase incondicional ao sistema fere a autonomia pela qual o homem lutou ao longo de toda a sua história e alcançou decisivos avanços na modernidade.

Submissão e autonomia são os extremos da tensa relação entre sujeito e sistema. Diante do domínio do sistema sobre o sujeito, diante da real ameaça de falência do sujeito no contexto da supremacia do sistema, torna-se cada vez mais urgente resistir a essa avassaladora intervenção exercida sobre os diferentes meios de constituição da autonomia, especialmente a educação, que tanto pode servir à liberdade quanto ao domínio. Hoje se constata o crescente uso da educação em favor dos interesses sistêmicos em contraposição ao direito de todos e a despeito do dever do Estado com relaçáo ao pleno desenvolvimento da pessoa, seu preparo para o exercicio da cidadania e sua qualificação para o trabalho. Nesses termos, o exercício da formação humana para o exercício da cidadania e da ética deve estar em harmonia construtiva com a preparação para o trabalho. Esses são os preceitos que devem orientar as políticas públicas no campo da educação.

Editores da Revista Educação \& Sociedade

\section{Referências}

ADORNO, T.; HORKHEIMER, M. Dialética do esclarecimento. Rio de Janeiro: Jorge Zahar, 1985.

CHOMSKY, N. Quem manda no mundo? Sáo Paulo: Crítica, 1917.

DARDOT, P.; LAVAL, C. A nova razão do mundo: ensaio sobre a sociedade neoliberal. Sáo Paulo: Boitempo, 1916.

HONNETH, A. Befreiung aus der Mündigkeit. Frankfurt: Campus Verlag, 2002.

SENNET, R. A cultura do novo capitalismo. Rio de Janeiro: Record, 2015.

ZIZEK S. O sujeito incômodo: o sujeito ausente da ontologia política. Sáo Paulo: Boitempo, 2016. 